\title{
Can macular translocation be a satisfactory management of subfoveal choroidal neovascular membrane?
}

\author{
Árpád Bereczki' \\ Zsolt Bíró2 \\ I"Petz Aladár" County Teaching \\ Hospital, Department of \\ Ophthalmology, Györ, \\ Hungary; ${ }^{2}$ St Imre Hospital, \\ Department of Ophthalmology, \\ Budapest, Hungary
}

\begin{abstract}
Purpose: To report histopathological observations regarding one of our macular translocation cases.

Methods: We have performed macular translocation with 360 degree retinotomy since 1997, and limited macular translocation with or without subretinal membrane removal since 2002. One of our patients died on the fifth postoperative day, so extensive histological examination of the removed neovascular membrane and entire globe was performed.

Results: We found that pigment epithelium remained attached to the neurosensory retina during retinal separation, in which case the rotated fovea will be relocated in a partially devoided pigment epithelial zone. In addition, even after complete surgical removal of the membrane during macular translocation, large membrane remnants are still detectable by histological examination.
\end{abstract}

Conclusion: In our opinion, macular translocation is not a satisfactory management of subfoveal neovascular membranes, because of changes in the pigment epithelium during surgery, and large subretinal neovascular membrane remnants.

Keywords: age-related macular degeneration (AMD), choroidal neovascularization (CNV), choroidal subretinal membrane, macular translocation, histology

\section{Introduction}

Subfoveal choroidal neovascularization (CNV) is a common cause of visual loss in patients with age-related macular degeneration (AMD), and several other disorders. Macular degeneration is the leading cause of blindness in the older population, and it is becoming more and more prevalent (Machmer 1998). At present there is no treatment for dry type of macular degeneration; for treatment of the wet form several medical and surgical therapies have been introduced with better and better results (MPSG 1991, 1993; Ulbig et al 1993).

Photodynamic therapy with verteporfin had a significant treatment benefit in predominantly classic CNV (TAP Study Group 1999), and new drugs are en-route. The treatment of AMD associated with $\mathrm{CNV}$ is changing fundamentally with the introduction of pharmacologic interventions. Large prospective clinical trials have demonstrated that selective inhibition of vascular endothelial growth factor (VEGF) may effectively counteract the permeability and proliferative effects of this important stimulus of neovascular AMD. VEGF has been identified as one of the major triggering elements in the pathogenesis of CNV. It is released because of hypoxia, oxidative tissue damage, and inflammatory conditions and induces vascular barrier breakdown with leakage and proliferation of endothelial cells and neovascular growth.

Surgical removal of the subretinal membrane has been attempted, but although the technique seemed promising, in many cases visual acuity did not improve. Machemer 
and Steinhorst (1993) have proposed another technique where after surgical removal of the subretinal membrane the fovea is translocated to an area with healthier pigment epithelium, Bruch's membrane, and choroid. Variants have been described, such as detachment of only the temporal part of the retina, or a retinal detachment was created in the temporal side through the sclera without retinotomy.

\section{Methods}

We analyzed the fixed tissue, taken at operation from one case in the Ophthalmic Pathology Laboratory of the Semmelweis University, Department of Ophthalmology, in which we performed a macular translocation using the Machemer and Steinhorst technique, with some modifications from Eckardt (Eckardt and Eckardt 1999, 2002; Eong et al 2001; Pertile and Claes 2002; Eckardt et al 2004), and from our own experience. We attempted to remove the entire membrane, which was fixed in $10 \%$ neutral buffered formalin and processed for routine microscope examination. After surgery we usually see a retinal fold starting from the optic disc and extending to the periphery, but this fold usually disappears after 5-7 days.

Our patient died (from intracranial hemorrhage) on the fifth day after surgery, and it was possible to perform histological examination on the operated eye.

At gross examination, we found that rotation had been achieved through an angle of 25-30 degrees. The next step was to perform sections of the translocated macula in the region of former subretinal membrane, as well as in the excised membrane, and our findings are discussed below.

\section{Results}

Extensive histological examination of the post-mortem enucleated globe revealed that the macula was relocated upwards by about 30 degrees to a place where no choroidal neovascular membrane was present.

We are able to show that, even after surgical removal of the membrane during macular translocation with 360-degree retinotomy, subretinal neovascular membrane remnants with thick-walled and dilated vessels can be seen. There are still some retinal pigment epithelial (RPE) cells attached to the residual membrane. The overlying retina shows only one row of ganglion cells, which indicates that this is not the macular area.

The retinal pigment epithelium has partly remained attached to the rotated retina. At higher magnification migration of the RPE cells towards the retina can be observed (Figure 1).

Tears in the RPE are present, which are more frequently detected in disciform scars. The RPE layer ends abruptly. The components of the disciform scar in the Bruch's membrane and subretinal area have become continuous. A vessel from the subretinal neovascular membrane can be seen extending into the subretinal space.

As we expected we found a thickened Bruch's membrane, few points of calcification, some remnants from the surgically removed subretinal membrane underneath and above the pigment epithelium (Bereczki et al 2000) as well as choriocapillary atrophy.

The outer retina seems not to be affected at the time of surgery.

From our point of view, it was of interest to examine the attachment of the pigment epithelium to the retina or Bruch's membrane along the temporary postoperative retinal fold. We found that the pigment epithelium was attached to the retina and Bruch's membrane (Bereczki et al 2000) (Figure 2) and we were able to follow this from the optic disc through the macular region up to the temporal periphery.

Even at the site of one of our retinotomies, which was performed in the line of retinal fold, we found the same picture. This can be caused by the presence of subretinal proliferation before surgery, or more probably provoked by surgery. This is supported by the wide extent of this finding.

Extensive histological examination of the intraoperatively removed subfoveal CNV membrane showed newly formed capillaries within a fibrotic stroma. Pigmented cells are plentiful. Some of the pigmented cells are derived from the retinal pigment epithelium, but others stained for hemosiderin with a Prussian blue stain and therefore are hemosiderin-loaded macrophages. The membrane also contains collagen and mucopolysaccharide materials.

The RPE cells are located on one side of the neovascular membrane but they are also seen inside the same structure which itself is densely fibrotic and contains a myriad of new vessels. A fragment of Bruch's membrane thickened by basal linear deposit can also be seen. It is not always possible to determine the exact location of the membrane (Figure 3 ).

\section{Discussion}

Subfoveal CNV is a common cause of visual loss in patients with AMD, and several other disorders. Macular degeneration is the leading cause of blindness in the older population, and it is becoming more and more prevalent. Surgical removal of this neovascular membrane has been proposed as an alternative method of treatment. Although improvement of surgical technique, diminishing numbers of surgery-linked complications have been observed by both our and international experiences, 


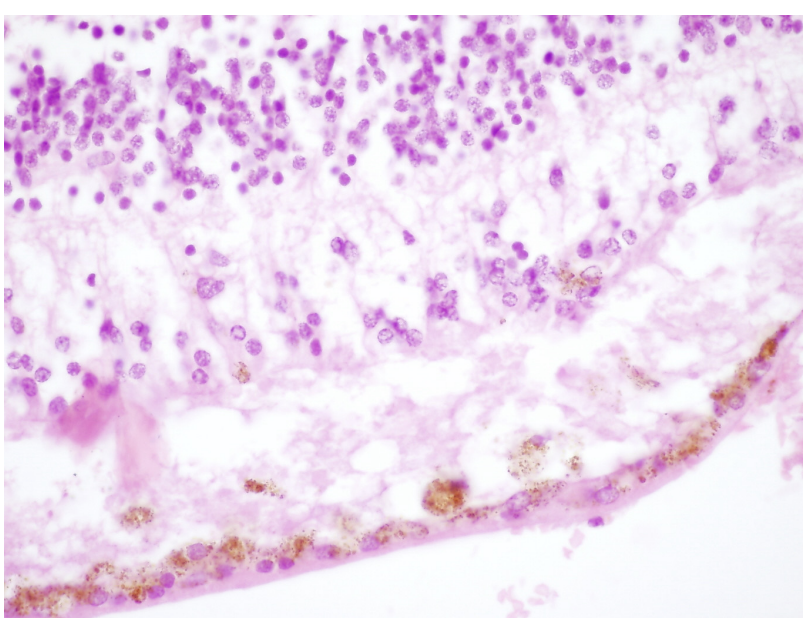

Figure I Migration of the RPE cells towards the retina, the photoreceptor layer is disorganized, and there is an RPE detachment. Hematoxylin and eosin, original magnification $\times 16$.

the visual prognosis for patients with surgically excised membranes after macular translocation surgery is variable (Eckardt and Eckardt 1999, 2002; Eong et al 2001; Pertile and Claes 2002; Eckardt et al 2004) and we have to deal with an increased number of recurrences (Bereczki et al 2000; Abdel-Meguid et al 2003; MacLaren et al 2005).

We also know from Grossniklaus and colleagues (Grossniklaus and Gass 1998; Grossniklaus et al 2002) that different membrane types will probably have a different impact regarding the histopathological changes after macular translocation surgery.

From our point of view, it was of interest to examine the attachment of the pigment epithelium to the retina or Bruch's

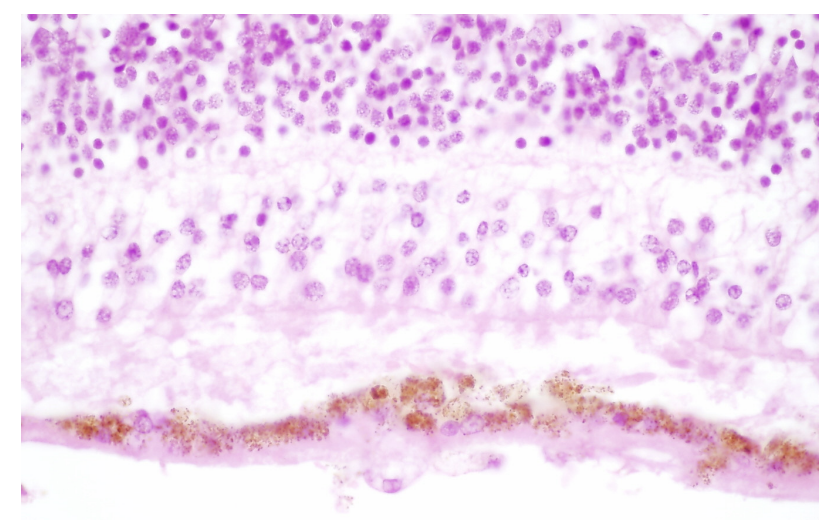

Figure 2 Pigment cells attached to Bruch's membrane, which is rather damaged. Hematoxylin and eosin, original magnification $\times 16$.

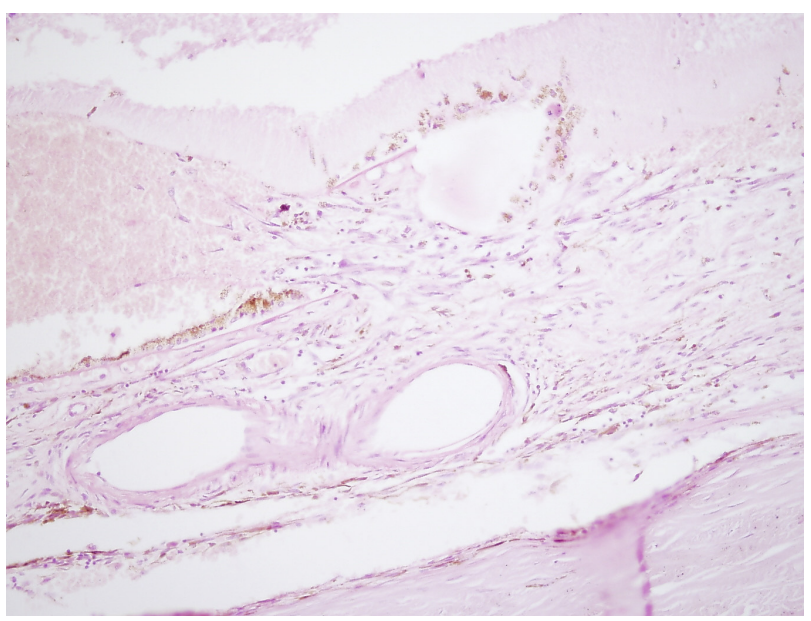

Figure 3 Subfoveal choroidal neovascular membrane. Hematoxylin and eosin, original magnification $\times 16$.

membrane along the temporary postoperative retinal fold. We found that the pigment epithelium was mainly attached to the retina and not to the Bruch's membrane. We were able to follow this attachment from the optic disc through the macular region up to the temporal periphery. Even at the site of one of our retinotomies, which was performed in the line of the retinal fold, we found the same histological picture.

Attachment of the pigment epithelium to the retina or Bruch's membrane can be caused by the presence of subretinal proliferation before surgery, but probably occurred during surgery. This is supported by the wide extent of this finding. We do not know if these changes may occur during the postoperative period of five days.

We know that there is no improvement in visual acuity in some cases after surgery, and we hypothesize that this is because of a significant part of the pigment epithelium has been translocated along with the retina.

From our histological sections we see that some part of the membrane remains in place even after surgical "removal" and we could see that the remaining membrane is a mixed one with extensions deep into and superficial to the pigment epithelium.

We tentatively believe that this may be connected with the fact that the pigment epithelium remained attached to the retina. In a type 1 subretinal membrane situated only above the pigment epithelium, this would not occur.

More research is needed to discover if there is any connection between the type of membrane, related to the condition of the pigment epithelium, and the apparent stronger adhesion between the pigment epithelium and retina (or relatively weaker adhesion to Bruch's membrane), but in our opinion 
macular translocation can not be a satisfactory management of subfoveal chorioidal neovascular membrane.

\section{Acknowledgments}

The authors acknowledge the efforts of Jeannett Toth MD, Semelweis University, Budapest, Department of Ophthalmic Pathology. There are no conflicts of interest to report.

\section{References}

Abdel-Meguid A, Lappas A, Hartmann K, et al. 2003. One year follow up of macular translocation with 360 degree retinotomy in patients with age-related macular degeneration. Br J Ophthalmol, 87:615-21.

Au Eong KG, Pieamici DJ, Fujji GY, et al. 2001. Macular translocation: unifying concepts, terminology, and classification. Am J Ophthalmol, 131:244-53.

Bereczki A, Toth J, Suveges I. 2000. Histological examination of the pigment epithelium-Bruch membrane-chorio-capillaris complex after macular translocation. Br J Ophthalmol, 84:550-1.

Eckardt C, Eckardt U, Conrad HG. 1999. Macular rotation with and without counter-rotation of the globe in patients with age-related macular degeneration. Graefes Arch Clin Exp Ophthalmol, 237:313-25.

Eckardt C, Eckardt U, Groos S, et al. 2004. Macular translocation in a patient with adult-onset foveomacular vitelliform dystrophy With light- and electron-microscopic observations on the surgically removed subfoveal tissue. Graefes Arch Clin Exp Ophthalmol, 242:456-67.

Eckardt C, Eckardt U. 2002. Macular translocation in non-exudative agerelated macular degeneration. Retina, 22:786-94.

Grossniklaus HE, Gass JMD. 1998. Clinicopathologic correlations of surgically excised type 1 and type 2 submacular choroidal neovascular membranes. Am J Ophthalmol, 126:59-69.

Grossniklaus HE, Brooks HL Jr, Sippy BD, et al. 2002. Retinal translocation and photodynamic therapy for age-related macular degeneration with classic choroidal neovascularization: a clinicopathologic case report. Retina, 22(6):818-24.
Machemer R, Steinhorst UH. 1993. Retinal separation, retinotomy, and macular relocation, I: experimental studies in the rabbit eye. Graefes Arch Clin Exp Ophthalmol, 231:629-34.

Machemer R, Steinhorst UH. 1993. Retinal separation, retinotomy, and macular relocation, II: a surgical approach for age-related macular degeneration? Graefes Arch Clin Exp Ophthalmol, 231:635-41.

Machemer R. 1998. Macular translocation [editorial]. Am J Ophthalmol, 125:698-700.

MacLaren RE, Bird AC, Sathia PJ, et al. 2005. Long-term results of submacular surgery combined with macular translocation of the retinal pigment epithelium in neovascular age-related macular degeneration. Ophthalmology, 112:2081-7.

[MPSG] Macular Photocoagulation Study Group. 1991. Argon laser photocoagulation for neovascular maculopathy: five-year results from randomised clinical trials. Arch Ophthalmol, 109:1109-14.

[MPSG] Macular Photocoagulation Study Group. 1991. Laser photocoagulation of subfoveal neovascular lesions in age-related macular degeneration: results of a randomised clinical trial. Arch Ophthalmol, 109:1220-31.

[MPSG] Macular Photocoagulation Study Group. 1993. Laser photocoagulation of subfoveal neovascular lesions of age-related macular degeneration: updated findings from clinical trials. Arch Ophthalmol, 111:1200-9.

[MPSG] Macular Photocoagulation Study Group. 1991. Subfoveal neovascular lesions in age-related macular degeneration: guidelines for evaluation and treatment in the macular photocoagulation study. Arch Ophthalmol, 109:1242-57.

Pertile G, Claes C. 2002. Macular translocation with 360 degree retinotomy for management of age-related macular degeneration with subfoveal choroidal neovascularization. Am J Ophthalmol, 134:560-5.

TAP Study Group. 1999. Photodynamic therapy of subfoveal choroidal neovascularisation in age-related macular degeneration with verteporfin. Arch Ophthalmol, 117:1329-45.

Ulbig MW, McHugh DA, Hamilton AMP. 1993. Photocoagulation of choroidal neovascular membrans with a diode laser. Br J Ophthalmol, 77:218-21. 